7 van der Werf C, Onderwater AT, van Langen IM, Smets EM: Experiences, considerations and emotions relating to cardiogenetic evaluation in relatives of young sudden cardiac death victims. Eur J Hum Genet 2014; 22: 192-196. of cause and manner of death via a comprehensive cardiac autopsy including whole exome next-generation sequencing. Arch Pathol Lab Med 2013; 138: 1083-1089.

9 Vuori E, Pelander A, Rasanen I, Juote M, Ojanpera I: A rare case of serial killing by poisoning. Drug Test Anal 2013; 5: 725-729.
8 Loporcaro CG, Tester DJ, Maleszewski JJ, Kruisselbrink T, Ackerman MJ: Confirmation

10 Lee SB, Clabaugh KC, Silva B et al: Assessing a novel room temperature DNA storage medium for forensic biological samples. Forensic Sci Int Genet 2012; 6: 31-40.

11 Fowler KE, Reitter CP, Walling GA, Griffin DK: Novel approach for deriving genome wide snp analysis data from archived blood spots. BMC Res Notes 2012; 5: 503.

12 Kauferstein S, Kiehne N, Jenewein T et al: Genetic analysis of sudden unexplained death: a multidisciplinary approach. Forensic Sci Int 2013; 229: 122-127.

\section{Reply to Sajantila and Budowle}

European Journal of Human Genetics (2016) 24, 330; doi:10.1038/ejhg.2014.290; published online 14 January 2015

We thank Drs Sajantila and Budowle ${ }^{1}$ for raising this interesting and important topic. They correctly point out that our Recommendations for reporting results of diagnostic genetic testing ${ }^{2}$ do not cover the special circumstances surrounding the reporting of post-mortem genetic testing. We did not consider this issue while preparing our recommendations, focusing instead on reporting of routine genetic testing (biochemical, cytogenetic and molecular genetic). Although some of our recommendations will apply to all reports of genetic testing, there may be important exceptions when post-mortem results are being reported.

The issues around post-mortem genetic testing and 'molecular autopsy' go far beyond the reporting of results, encompassing inter alia issues of consent, sample integrity, legal custody and retention/storage of tissues. We understand that the Professional and Public Policy Committee (PPPC) of the ESHG is currently considering these issues with a view of producing a policy statement. The Genetics Services Quality Committee fully supports this initiative and looks forward to commenting on the draft statement when available.

\section{CONFLICT OF INTEREST}

The authors declare no conflict of interest.

David E Barton ${ }^{1}$, Mireille Claustres ${ }^{2}$, Viktor Kozich ${ }^{3}$, Els Dequeker ${ }^{4}$, Brian Fowler ${ }^{5}$, Jayne Y Hehir-Kwa ${ }^{6}$, Konstantin Miller ${ }^{7}$,

Cor Oosterwijk ${ }^{8}$, Borut Peterlin ${ }^{9}$, Conny van Ravenswaaij-Arts ${ }^{10}$, Uwe Zimmermann $^{11}$, Orsetta Zuffardi ${ }^{12}$ and Rosalind J Hastings ${ }^{\star, 13}$
${ }^{1}$ National Centre for Medical Genetics, School of Medicine \& Medical Sciences, University College Dublin,

Our Lady's Children's Hospital, Dublin, Ireland;

${ }^{2}$ Molecular Genetics of Rare Disorders, University Hospital of Montpellier and INSERM U827, IURC (Institut Universitaire de Recherche Clinique), Montpellier, France;

${ }^{3}$ Institute of Inherited Metabolic Disorders, First Faculty of Medicine, Charles University in Prague, Prague, Czech Republic;

${ }^{4}$ Biomedical Quality Assurance Research Unit, Department of Human Genetics, University of Leuven, Leuven, Belgium;

${ }^{5}$ Department of Paediatrics, Universitats-Kinderspital Beider Basel

(UKBB), Basel, Switzerland;

${ }^{6}$ Department of Human Genetics, Radboud University Medical Centre, Nijmegen, The Netherlands;

${ }^{7}$ Institute of Human Genetics, Hannover Medical School, Hannover, Germany;

${ }^{8}$ VSOP-National Patient Alliance for Rare and Genetic Disorders, Soest, The Netherlands;

${ }^{9}$ Division of Obstetrics and Gynecology, Clinical Institute of Medical Genetics, University Medical Center, Ljubljana, Slovenia;

${ }^{10}$ Department of Genetics, University of Groningen, University Medical Centre Groningen, Groningen, The Netherlands;

${ }^{11}$ Division 3 Health/Forensics, Deutsche Akkreditierungsstelle GmbH (DAkkS), Frankfurt am Main, Germany;

${ }^{12}$ Department of Medical Genetics, University of Pavia, Pavia, Italy;

${ }^{13}$ CEQAS, John Radcliffe Hospital, Oxford University Hospitals NHS Trust, Oxford, UK E-mail: Ros.Hastings@ouh.nhs.uk

1 Sajantila A, Budowle B: Postmortem medicolegal genetic diagnostics also require reporting guidance. Eur J Hum Genet 2014; e-pub ahead of print 3 December 2014; doi:10.1038/ejhg.2014.247.

2 Claustres M, Kozich V, Dequeker E et al: Recommendations for reporting results of diagnostic genetic testing (biochemical, cytogenetic and molecular genetic). Eur J Hum Genet 2014; 22: 160-170. 